\title{
Quality Accreditation of Engineering Education. Issues on an Optimal Accrediting Agency Model
}

\author{
Hugo J. Pirela Martínez, Ph.D. ${ }^{1}$ \\ ${ }^{1}$ Greater Caribbean Regional Engineering Accreditation System, GCREAS, Dominican Republic, hpirela@gmail.com
}

\begin{abstract}
This paper analyzes in detail the features that set accreditation apart from other qualification processes -i.e the ones relating to graduation and licensure of engineers- as a quality marker of engineering education, in terms of its social function and underpinnings; degree of mandate; and geographical scope. Based on this analysis the author argues for: (i) outcome-oriented approach to accreditation; (ii) demand-driven criteria for judging quality; (iii) profession-controlled organization; (iv) internationally homogeneous standards; and (v) orientation toward the Washington Accord, as key features of an optimal institutional model for agencies accrediting the quality of engineering education.
\end{abstract} model.

Keywords - accreditation, graduation, quality, institutional

Digital Object Identifier (DOI): http://dx.doi.org/10.18687/LACCEI2015.1.1.196

ISBN: 13 978-0-9822896-8-6

ISSN: 2414-6668

13 $^{\text {th }}$ LACCEI Annual International Conference: “Engineering Education Facing the Grand Challenges, What Are We Doing?” July 29-31, 2015, Santo Domingo, Dominican Republic ISBN: 13 978-0-9822896-8-6

ISSN: 2414-6668

DOI: http://dx.doi.org/10.18687/LACCEI2015.1.1.196 


\title{
Quality Accreditation of Engineering Education. Issues on an Optimal Accrediting Agency Model
}

\author{
Hugo J. Pirela Martínez, Ph.D. \\ Greater Caribbean Regional Engineering Accreditation System, GCREAS, Dominican Republic.
}

\begin{abstract}
This paper analyzes in detail the features that set accreditation apart from other qualification processes -i.e the ones relating to graduation and licensure of engineersas a quality marker of engineering education, in terms of its social function and underpinnings; degree of mandate; and geographical scope. Based on this analysis the author argues for: (i) outcome-oriented approach to accreditation; (ii) demand-driven criteria for judging quality; (iii) professioncontrolled organization; (iv) internationally homogeneous standards; and (v) orientation toward the Washington Accord, as key features of an optimal institutional model for agencies accrediting the quality of engineering education.
\end{abstract}

\section{THE NATURE OF QUALITY ACCREDITATION}

The certification procedures associated with the quality accreditation of education programs or institutions arguably yield the uppermost marker for quality assurance in the field of engineering. In an idealized "general quality assurance scale", other qualification procedures can be viewed as providing more basic, cumulative qualification markers, which are requisite conditions for the accreditation to build upon; namely: (i) the certification procedures that grant educational institutions the right to issue individual degrees (graduation); and (ii) the certification procedures associated with awarding individual graduates the right to exercise the profession (licensure). The horizontal lines on figure 1 represent the level of each of the referred "qualification markers" on the quality scale, and the vertical vectors depict the level that could be reached beyond graduation ${ }^{1}$

Accordingly, only those ablest students, in those certified institutions, might reach graduation; only those

\footnotetext{
${ }^{1}$ Some might object to this comparison over a common scale, on the grounds that the object and purpose of the said procedures are completely different: i.e. accreditation refers only to educational institutions, or its programs, and only "by association" to the professional as a person; while the other qualification procedures focus either wholly on the individual (certification associated with granting a professional license) or concern both the institution and the individual (certification associated with granting a professional degree). Nevertheless, a generalized common quality scale is justified presently in the sense that all these qualification procedures can be said to contribute to better engineers and better engineering in general.
}

ablest graduates might eventually reach licensure; and only those ablest institutions might eventually reach accreditation; with the last marker not necessarily providing professional competencies in addition to those afforded by the first two, but purportedly representing the highest degree of potential quality of outcomes from an active engineer, given the current state of art within each professional competency. Besides its different nature as marker in the generalized quality scale, the accreditation also distinguishes itself from the other two more basic quality markers in other important respects, such as its social function and underpinnings, as well as its degree of mandate and geographical scope.

\section{A. Social function.}

Unlike the certification criteria associated with graduation and licensure, which are essentially criteria minima -i.e. a fixed, "quality floor" of parameters, minimally required for compliance- and do not necessarily concern themselves with maximizing quality, the certification criteria associated with accreditation by nature aim at pushing upward the "quality ceiling" -which, therefore, becomes of necessity a moving target- and do not stop at merely assuring compliance with fixed minimum requirements. In this sense, the social function of accreditation is, therefore, more of quality promotion and continuous improvement, rather than solely of minimal quality assurance.

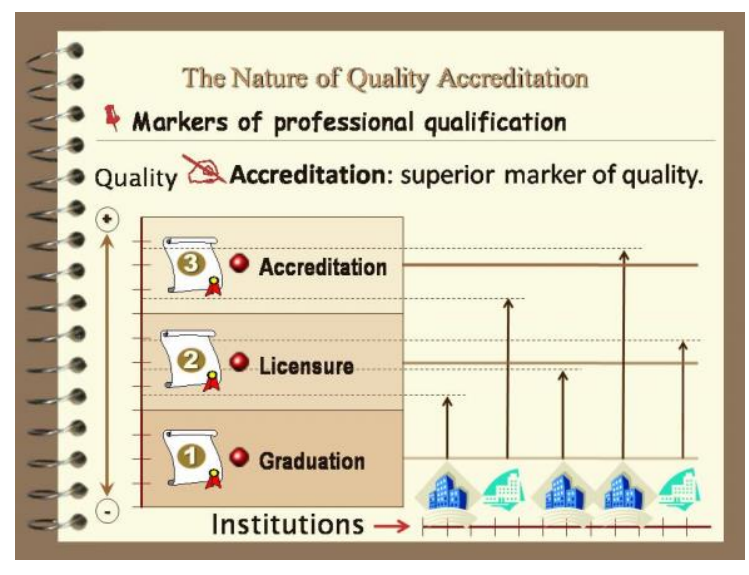

Fig.1: A generalized scale for engineering qualification 


\section{B. Social underpinnings}

Although the general quality of engineering can be said to be in the interest of all social actors, it can also be argued that each qualification marker is naturally anchored in the interest of a particular class of stakeholders, which preponderantly focuses on it. For instance, the requirement for institutions to be minimally certified to grant graduation at College or University level is naturally born out of the social need for the providers of education to comply with minimum conditions, homogeneous for all concerned parties, as to avoid unfair competition on the supply side of the market for quality in engineering. The stakeholder of focus at this quality marker level is, therefore, Academia. A similar argument can be made about the minimal-requirement certification process associated with licensure, which is chiefly born out of the need of another key quality stakeholder partaking in the supply side of the market for quality engineering, and which is also interested in avoiding unfair competition therein, namely: the Profession itself. In contrast, it can be easily seen that the need to not only guarantee minimum compliance but to maximize quality, which is normally associated with the accreditation process, is naturally born out in the demand side of the market for quality engineering. Society itself, as the ultimate customer of engineering, demands criteria maxima for quality and the Employer Sector, which puts engineers to work, is the stakeholder of focus pushing for maximum quality at this marker level. The curved vectors in figure 2 illustrate the nexus of each quality marker with its key social stakeholders.

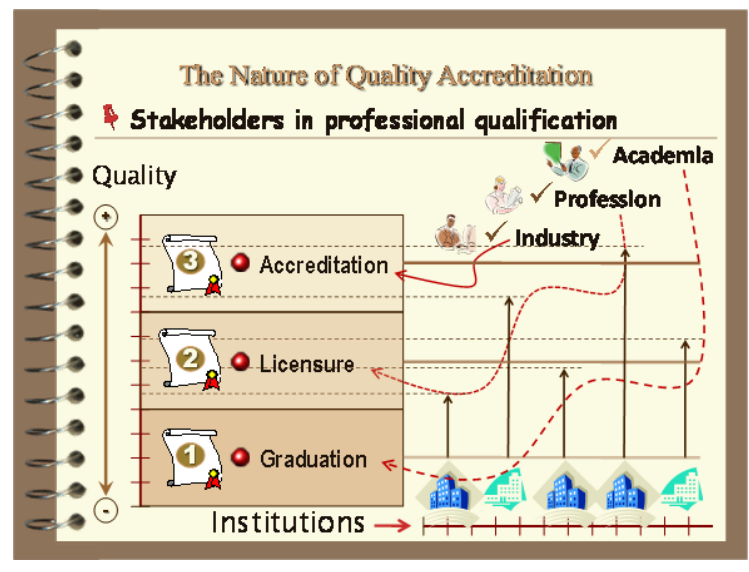

Fig.2: Key social stakeholders in the quality of engineering

\section{Degree of mandate.}

The social function of the several markers of quality assurance is clearly associated with their particular social underpinnings, as the foregoing argument shows. Another attribute, also closely associated to the previous two, sets the accreditation process apart from the other quality assurance procedures in the field of engineering. This attribute relates to the degree of mandate that each qualification marker entails.

To be certified to grant graduation is a mandatory condition, concerning both individuals and institutions, for lawful involvement in the supply side of the engineering market. Also the certification process for licensure constitutes a sine qua none requirement for individual graduates to get legally involved in providing professional services. The process for accreditation is, on the contrary, an essentially voluntary one whose absence does not preclude individuals or institutions from freely acting in the market for quality engineering. ${ }^{2}$ Accreditations, therefore, mostly constitutes an option for those eligible stakeholders wishing to strive further up the quality assurance scale, and become more competitive. As mentioned, the vertical vectors in figures 1 and 2 represent the various levels that individual graduates from the various educational institutions may be able to reach in the quality scale, chiefly on the account of their own capabilities, directly or by association. Yet, the vectors reaching towards the highest marker (accreditation) represent a function not only of the capabilities but also of the choice made by particular institutions to reach out for the highest quality possible in engineering education.

\section{Geographical scope.}

The certification procedures for graduation and licensure tend to be also anchored in national conditions and markets, and are normally scripted in national legislation. The idiosyncratic nature of such conditions, markets and legislations in each country make graduation and licensure processes mostly national in purpose and jurisdiction, and it is the main reason behind the fact that normally no professional degree or license is necessarily or automatically transferable across national borders. This argument, however, loses relevance in the case of accreditation.

\footnotetext{
${ }^{2}$ Some visible evolution in educational incentive systems of advanced countries, such as USA and Canada, is progressively making the accreditation of programs and institutions more of a requisite -for instance, to apply for certain institutional grant money- and there is also a trend in some countries to align accreditation and licensure criteria. On the other hand, highly prestigious educational institutions worldwide do not apply at all for accreditation and this quality assurance procedure remains for the most part voluntary, concerning legal operation in the market.
} 
In the economy of the XXI century is not unusual for engineers from one country to construct buildings, bridges, roads, etc. on another country; nor is it unusual for spare parts, industrial inputs, etc. produced in one country, to be used in another country for the repair of equipment and manufacturing of products destined for consumption in yet another country. As markets become universal and -pushed by economic and technological globalization- production turns increasingly multinational in nature, the need becomes clearer for the existence of internationally homogeneous standards to ensure the quality both of the engineering processes and of the engineers in charge of those processes in any country. This is causing the quality accreditation of educational programs and institutions which are restricted to national boundaries to become increasingly irrelevant for today and tomorrow's markets. Also, even under the best conditions of knowledge and academic preparation, given a number of other development considerations -as well as social and economic endowment externalities that vary from country to country- it is not reasonable to expect the same "average" level of quality in the educational outcomes of engineering in all countries.

This different quality of outcomes between countries akin to the kind of outcome differences normally observable between students or colleges, due to equivalent development and endowment variations- is illustrated in figure 3. The relative disparities in externalities resulting in some countries yielding better average engineering outcomes than others are very real, but also increasingly untenable.

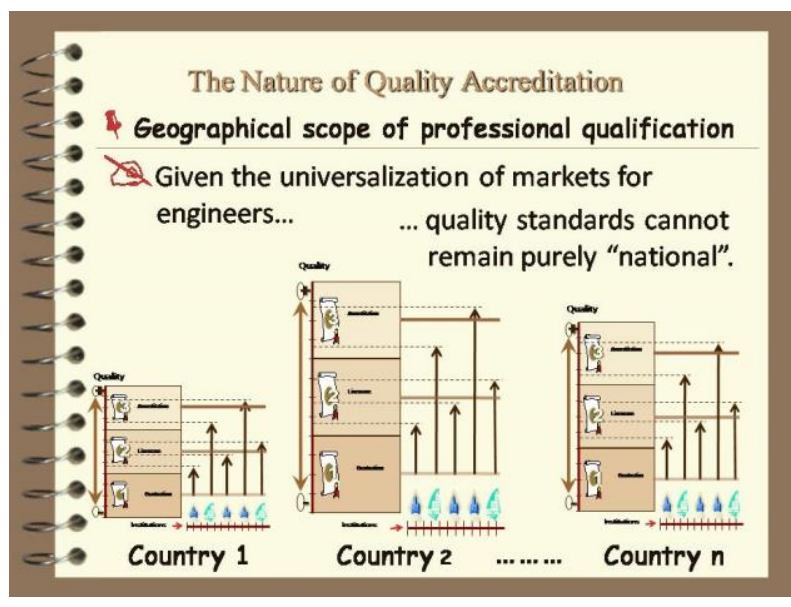

Fig.3: Different national outcomes due to disparate endowments.

Certainly in the past, engineers tended to work only locally in the countries where they were trained and follow the particular standards of those countries. However, the frequency and nature of economic interchange between countries have been rapidly changing in the last decades and, as professional mobility increases, the quality of engineers is less and less a purely "national" issue, and more of an international requisite for competence and competitiveness in the world economy. Therefore, the need for Universities to guarantee in each country the education of internationally competent and competitive engineers makes evident the need for their respective programs to be evaluated and accredited on the basis of internationally recognized quality standards, such as, for instance, those agreed upon in the Washington Accord. Indeed, the set of standards adopted through substantial equivalence agreements between the countries signatories of the Washington Accord is a prime example of such homogeneous international requirements for accreditation, and is illustrated with the horizontal line dissecting the upper segment of the quality axis in figure 4 .

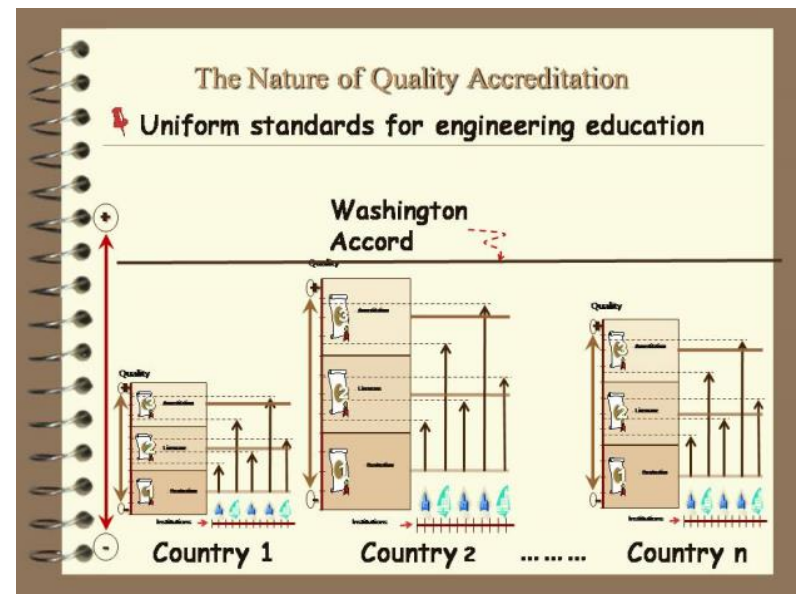

Fig.4: The Washington Accord: example of international standards

\section{OPTIMIZING AN INSTITUTIONAL MODEL FOR ENGINEERING ACCREDITATION}

From the premises outlined in the previous discussion, some conceptual lines can be derived with a view to optimize an institutional model for agencies accrediting engineering education, in terms of: (i) focus; (ii) rational: (iii) institutional grounding; (iv) jurisdiction; and (v) standards.

\section{A. Focus of accreditation}

The facts that society at large is the ultimate customer and judge of quality, and that it is basically not interested in process, but in medium to long term results, are sufficient arguments to support the current consensus that assuring the 
quality of engineering education cannot stop merely at controlling the quality of educational inputs and outputs -a process that occurs entirely within college campuses, and constitutes the more traditional basis to judge the quality of the engineering programs. Today it is generally admitted that the accreditation of institutions and programs of learning must also assure the quality of educational effects -the sometimes called "learning outcomes"- which are the ultimate measure of quality for the engineers themselves and for the real work they do for society; something that, of necessity, cannot be truly ascertained but outside the boundaries of college campuses.

In other words, because the first trench for assessing the quality of learning cannot fall but within the curfew of the education business, it is understood that the immediate focus of accreditation must be the quality of the educational process itself. However, it has been recognize that the true substance and commodity of the education accrediting business is what results after -and beyond- the educational process: a matter, thus, to be judged not only by Academia or merely by inference based on what has happened in the classrooms and laboratories, but also appraised separately and independently, with inclusion of other social stakeholders in the receiving end of results ${ }^{3}$.

Notice that this argument does not negate the validity of the educational process' internal criteria or standards for quality evaluation, such as comparing results intended (educational goals) with results obtained; efficiency and rationality in the use of resources to obtain the results; etc. as stipulated by models of prominent evaluation scholars such as that of Professor Stake ${ }^{4}$. Internally defined educational goals and evaluation criteria conform to the time-honored, universally recognized principle of University Autonomy. Yet, however valid the in house-defined goals and standards are for the educational process, accreditation agencies should

\footnotetext{
${ }^{3}$ Accrediting agencies in the frontline of this debate, pioneered by the USA Accreditation Board of Engineering \& Technology, ABET, have struggled with the dilemma that although "learning outcomes" cannot be fully tested and ultimately evaluated but in the actual professional exercise, in the mist of society and industry, there appears not to be any practical way of frequently and systematically assess the quality of such learning outcomes but to do it right before the educational process ends, by gauging the so-called graduate attributes. There is, however, an implicit recognition that such graduate attributes can only be proxy indicators of actual learning outcomes.

${ }^{4}$ See Stake, R. E. Standards-Based and Responsive Evaluation, Thousand Oaks, CA, Sage Publications, 2004
}

take note that being autonomous does not mean that colleges and high education programs must be isolated and separated from their social context. On the contrary, they must view colleges and high education programs as systems within a more complex system -the social system- honoring the open, independent nature of the education providers' trade, but stressing at the same time the need for their permanent interface and interchange with other social stakeholders.

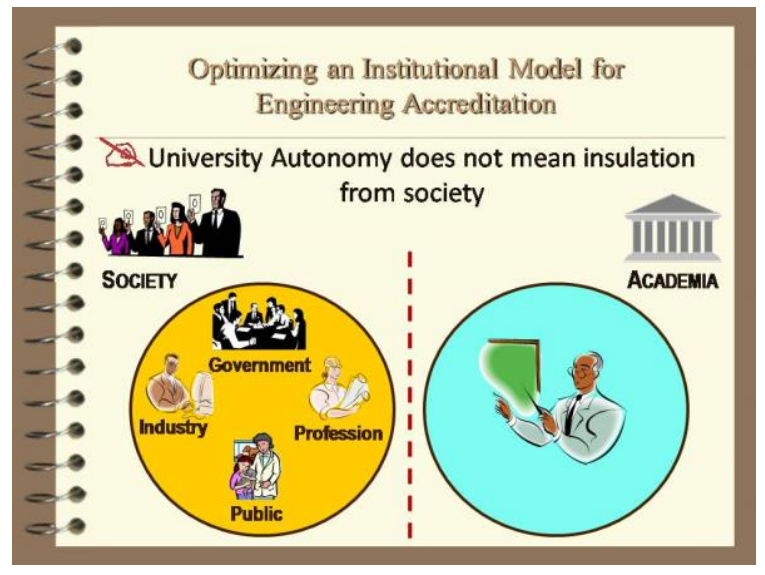

Fig.5: Accrediting the quality of education cannot be the sole business of the Academe, acting separately from society

This approach is also aligned with the modern worldwide tendency in the domain of evaluation that purports to judge actions and organizations not merely on account of the outputs they deliver in their immediate institutional realm, but principally by the effects (outcomes) such outputs induce in the social body as a whole, as well as other results they contribute to up the so called results chain, as has been defined through international consensus by the OECD's Development Assistance Committee. ${ }^{5}$

In the specific realm of engineering, this approach follows the pioneering steps of ABET; institution that spearheaded the primacy of outcomes concept in accrediting engineering education programs, when in 1996, through the so-called Engineering Criteria 2000 -known in the engineering education community simply as "EC200"-, began phasing out the exclusive emphasis on the program inward-looking criteria, traditionally used for accrediting engineering education, and introduced in its evaluation

\footnotetext{
${ }^{5}$ See modern, internationally agreed nomenclature on Results, Results Chain, Inputs, Outputs, Outcomes and Impacts in O.E.C.D DAC Working Party: Glossary of Key Terms in Evaluation and Results-based Management. pp. 33, 25, 28, and 24.
} 
standards and procedures the assessment of "learning outcomes". Specifically,

...the new criteria shifted the basis for accreditation away from resources, curricular equipment, faculty and facilities to what students had learned in their programs $^{6}$

In conclusion, the outcome-oriented approach to quality accreditation in education embraces the notions that: (i) engineering programs can be said to possess quality only if they lead to quality engineers actually graduating from them and performing accordingly in society; and (ii) this outcome must ultimately be validated separately and not only "inferred" from the quality of the teaching process.

\section{B. Rational of accreditation}

Closely related to the above argument is the notion that in judging the quality of education in engineering the point of view of the demand for quality must also have primacy over the point of view of the supply of it; and that, although the latter must always come into the mix -notice that we say "primacy", not "exclusivity"- this is another reason why the education accrediting agencies should not be organizations representing only the "providers" of high education services (Colleges, Government agencies, etc.).

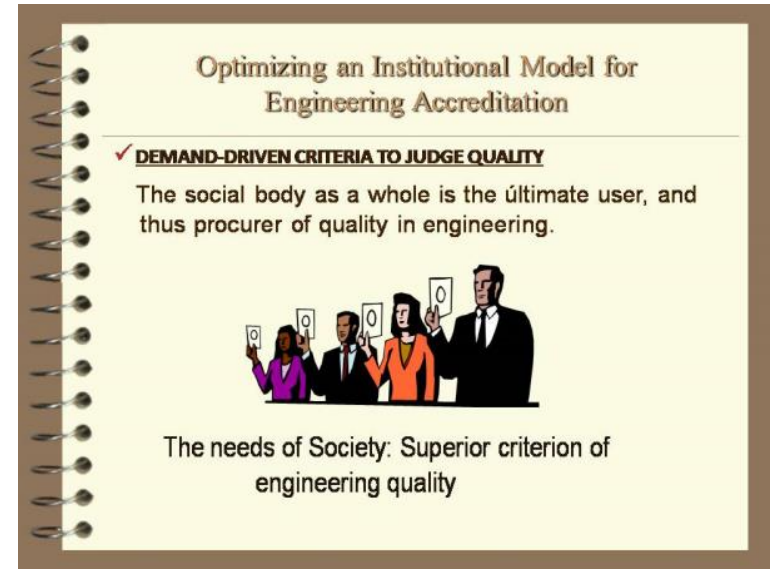

Fig.6: Society and its needs provide the ultimate criterion for quality

A demand-driven approach to accrediting the quality of education in engineering is what must materialize right out of the above mentioned interfacing of the educational

${ }^{6}$ See: Latucca., Lisa R., et al. Engineering Change. A study of the impact of EC2000. Center for the Study of Higher Education, Pennsylvania State University, 2006. p. 1 institutions with their social context; whereby academia interacts with the other stakeholders as a synergic part of the social whole, to continually tend to needs and improve results. Through such interfacing, the education programs' inputs (v.g. the curriculum, faculty, facilities, educational strategy and methods, etc. of the institutions, as applied to the teaching process) and their outputs (v.g. the resulting students' experience, both in-class and out-of-class, etc.) induce particular outcomes in the actual practice of engineering (as reflected in student learning, employer ratings, etc.) and this results chain revolves upon itself, feeding back the education programs, and starting the process all over again each time around. ${ }^{7}$

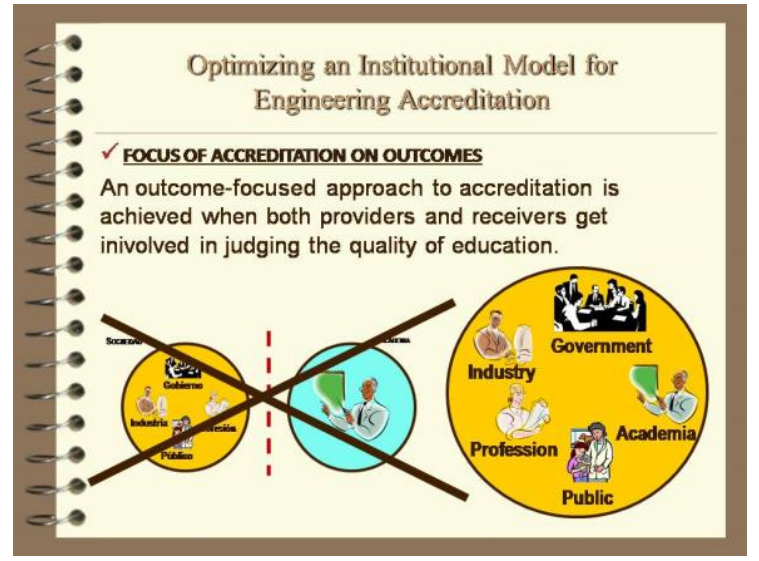

Fig.7: Academe acting not separately, but as a part of a synergic social whole in promoting and assuring the quality of education

An example of this iterative feed-back mechanism in action is the observed movement of practices of engineering accreditation from the input/output-based old model of quality evaluation to the more outcome-oriented model, spearheaded by ABET. This process was mostly demanddriven, as it precisely originated in the external context of Academia as a feedback from society in the USA to the high education community -often in the form of criticism- and in the response from the high education and accreditation community that ultimately resulted in the EC2000. Describing this feedback process on the quality of engineering education, the cited study of Penn State University reads:

\section{Employers complained that job applicants} demonstrated poor communication and teamwork

\footnotetext{
${ }^{7}$ See a depiction of this iterative process in Latucca., Lisa R., et al. Op. Cit. "Conceptual framework for Engineering Change", p. 4
} 
skills and little appreciation of the social and nontechnical influences of engineering solutions and quality processes [...]

Engineering schools responded slowly to these criticisms as deans of many colleges of engineering argued that rigid accreditation standards with strict prescriptions for curricula and credit hours thwarted change. In 1992, a representative of two groups of deans of major engineering schools met with the leaders of ABET to voice these concerns. Members of ABET's Industry Advisory Council shared the concerns of the engineering deans and employers and encourage a response from ABET's leadership. ${ }^{8}$

Accordingly, the quality of engineering education programs ultimately rests on the capacity of those programs to respond to social demands on the preparation of engineers, so that they are able to contribute to society through their actual professional practice; a capacity that must be secured by internal controls in the education process itself and its products (inputs, outputs), but that can ultimately be judged only by external criteria, established in the social and economic context (outcomes).

In conclusion, the organic involvement early in the inception and design of accrediting agencies of other social agents beyond Academia, interested in the quality of engineering education, such as Industry, Government and the Profession, as well as their action as accreditation authorities and through advisory bodies, and their participation in the actual evaluation process -for instance, through the opinion of key stakeholders, such as parents, private employers, etc.are advanced practices of optimal education accrediting systems that seek to articulate a demand-driven approach to the accreditation of quality in engineering education.

\section{Institutional grounding of accreditation}

There are cogent reasons not to desire institutions of accreditation purely designed and/or run by actors from the supply side of the education equation -not the least of which is the moral hazard and obvious possibility of conflict of interest. But there are also sensible arguments not to consider optimal those accreditation systems exclusively anchored in

${ }^{8}$ Latucca., Lisa R., et al. Op. Cit. p. 2 the demand side of the education equation, i.e. solely in industry or the private sector. The social need for wellbeing and betterment and not necessarily the public's "effective demand" -which might be artificially induced or otherwise manipulated- is the truly adequate basis against which the quality of engineering education and results should be judged. And in understanding the nature of true social needs, and technically apt solutions, the participation of the generators of authentic scientific knowledge, on the supply side of the equation, is indispensable. Securing proper social feedback and institutional response on the issue of engineering quality requires the participation of all the types of organizations organically involved in and/or affected by the issue. Only in that way a proper balance can be struck between supply and demand in the market for quality education in engineering. Such balance should be also sought in the internal governing structure and operation of the optimal systems for accreditation of engineering education

That said, the more advanced accrediting agencies in the world are profession-controlled organization. That is, while they are not institutionally anchored in academia, or in institutions of the industry, they give ample participation to both, in advisory roles and through expert participation in the accreditation business; yet, they recognize that professional associations are primus inter pares among the organization's stakeholders, in so far as the profession can be viewed as equally partaking in the supply and the demand side of the market for quality engineering education. The Profession, therefore, is considered the closest of all relevant stakeholders to the neutral needle of the balance of said market for quality engineering education.

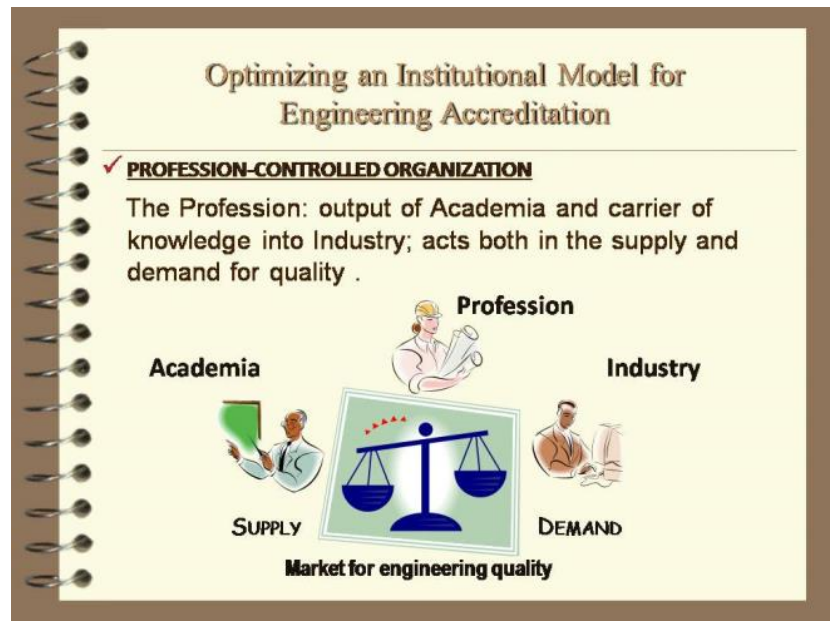

Fig.8: The Profession: the stakeholder that stands closest to the needle of the balance between supply and demand for engineering quality 
Certainly, in their capacity as direct outputs of academia in the domain of engineering, and the main conveyors of engineering knowledge and practices into the realm of industry, professional engineers are uniquely positioned and suited to oversee that the engineering education programs serve the outcomes demanded by society, and society in turns finds technically and scientifically appropriate answers in what concerns the quality of engineering practices and results.

Finally, and though so far we have made no explicit mention of the Government as an all important stakeholder in the quality of engineering, its relevance in the matter cannot be ignored. To the extent that it represents all social actors and sectors in modern nation-states, the government has undeniable responsibilities and authority in what concerns the control, assurance and promotion of quality in engineering and technology; not only as chief safeguards for society in matters of functionality, safety and standards of living, but also as a fundamental means for the integral development of countries, as has been recognized by the Organization of American States, OAS. ${ }^{9}$ Nevertheless, and in recognition of the uniquely advantageous position held by professional associations on the mater, in the most advanced countries this original overseeing authority has been reinstated by government upon the Profession itself, as a self-regulated purveyor of quality.

A profession-controlled model can also, more efficiently than any other form of institutional anchorage, insulate quality accrediting agencies from the dangers of real or perceived conflict of interest; especially in what relates to the financial sustainability of the organizations. Quality accreditation generally involves significant costs in terms of time, energy and financial resources, and securing the relevant services and their general maintenance and management on a sustainable basis normally requires the charging of fees that cannot be construed as "payment for award", lest the whole business of accreditation itself loses social credibility. ${ }^{10}$

\footnotetext{
${ }^{9}$ See: OAS, Declaration of Lima. $1{ }^{\text {st }}$ Meeting of Ministers and High Authorities of Science and Technology. REMCYT-I/DEC. 1/04. Nov 12, 2004

${ }^{10}$ The charting of accrediting agencies as non-for-profit organizations, the enforcing of only pro bono work by peer evaluators, and the systematic exclusion from evaluation teams, of peers that may have had a personal or work relation to the institution being evaluated, are regular practices by which accrediting agencies avoid individual conflict of interest. Yet, a potential "collective" conflict of interest can still be claimed, for instance, in the case of accrediting agencies lopsidedly controlled by the institutions which themselves are being accredited.
}

Arguably, the ways and means for any non-for-profit organization to achieve financial sustainability tend to fall between two extreme models: (i) the organization is regularly dependent for its functioning on the allocation of resources by another organization, or groups of organizations, as may be government institutions, international donor agency, national private institutions; or any other "sponsoring" entity; (ii) the organization covers all its operational costs by revenues generated internally, via charges for services (the "extreme self-reliant" scenario). In practice, a substantial number of organizations operate under some sort of combination of both, with inclusion of internal contributions.

Absolutely zero potential conflict of interest in quality accrediting agencies can only be guaranteed by complete independence from any single interested party and through the "extreme self-reliant" scenario identified above; provided the agency adheres to a non-for-profit legal charter, as well. Yet, this scenario appears practicable only in cases of large accreditation markets, which are able to provide a demand stream of critical mass sufficient for sustainable break-even; or in cases that the proceeds from an endowment or a service, separate and distinct from the business of accreditation, is stipulated at inception as a steady source of revenue to cover the organization's operational cost. Being these two conditions not always present or possible in combination with non-for-profit charters, the quality accrediting agencies are most frequently not completely self-reliable, and do depend on contributions from member institutions or individuals for sustenance and steady operation.

There is nothing intrinsically inappropriate for nonprofit education accrediting organizations to receive contributions from social stakeholders interested in their mission, such as universities, government agencies, private for-profit firms, etc. Yet, given the fact that financial contributions from interested parties are all but necessary for sustenance in most cases, and that financing from only one interested party always means a certain degree of exclusive control, the best practical scenario for quality accrediting agencies is to diversify as widely as possible its income sources, or to anchor its sustenance and control on the one stakeholder that have equal say in the supply and demand side of the market and, therefore, positions itself the farther from any real or perceived conflict of interest; namely: the Profession. 
In conclusion, though not all known engineering education accrediting agencies were born as professioncontrolled organizations, the preponderant role of the profession in the business of quality accreditation of engineering education should be recognized and promoted for optimal operation in the trade.

\section{Jurisdiction of accreditation}

By the arguments advanced in section C of Chapter I of the present essay, the accreditation of quality in engineering education, in the present economy and society, is increasingly irrelevant unless is international in scope (i.e. the accrediting party should ideally have equivalent recognized authority beyond particular national borders as it has within the country where it is chartered and headquartered). Paradoxically, given the general legal and jurisdictional barriers involved, the majority of existing accrediting agencies, including the most advanced ones, are national by charter. Nevertheless, the intention and decisive trend toward internationalization is clearly coming to the front, through mutual recognition agreements of substantial equivalence of rules between agencies, and through the emergence of regional agencies and systems.

Current international agreements do, in fact, accept jurisdictions for accreditation of engineering education other than that of a "country", with the inclusion of figures such as "region", "territory" and "economy"; creating thus the possibility of systems involving multiple national agencies or jurisdiction on the matter. The multi-national jurisdiction model derives from the premise that none of the involved countries by themselves has an appropriate critical mass enough number of engineering programs- to achieve an independent accreditation system which can be selfsustainable in the long run. Now, while solving at the regional level the national "economics of scale" issue, regional systems also create the challenge of potential conflicts between national and regional authority, criteria, policies and procedures concerning the accreditation of engineering education. In such cases the institutional viability hinges on the willingness of national stakeholders to recognize the systems authority in what concerns regional engineering accreditation, and to align their national criteria, policies and procedures on the matter, with those of the regional system.
Now, since quality accreditation of engineering is an optional process which stakeholders of different territories or social functions may voluntarily organize around, and interested colleges or programs may engage in on a voluntary basis, in practice nothing precludes the existence of more than one accreditation system overlapping a given market. The case can even be made that, on the contrary, in some circumstances it might be in the interest of the programs and institutions to have more than one system -national or international- to choose from, to encourage better services through competition, or the possibility of more than one accreditation to add to the pedigree. This, however, does not appear to be a steady state, long term efficient solution.

For reasons of costs, required institutional efforts and need for homogeneity in standards, most probably it is in the interest of colleges and programs within a country or a region to share a single accreditation system of reference, if at all possible. And, from a purely financial feasibility point of view, the long-term, steady state solution to the problem of competing national or regional accreditation systems may only be a "market solution", with the equilibrium to be determined by the complex interplay of variables such as effective demand (critical mass of programs), economics of scale, costs ratios, credible independence and selfsustainability. This is not to say, however, that extraeconomic factors, such as political motivations, cultural differences, sub-regional sensitivities, etc. may play a role in establishing and forcing over the long-run non marketequilibrium, less efficient, solutions. Anyway, whatever the steady-state response may result to the potential challenge of regional jurisdictional overlapping, a policy of mutual collaboration and synergy between agencies makes sense from the point of view of developmental efficiency

In conclusion on the jurisdiction matter, a commitment to international, homogeneous rules and standards, via adherence to multinational substantial equivalence agreements or via feasible regional jurisdictions as such, appears to be a desirable feature of the optimal institutional model for agencies accrediting the quality of education in the realm of engineering.

\section{E. Standards of accreditation}

Last, but not least, it must be pointed out that agencies accrediting the quality of education in engineering within the Americas have in the Washington Accord a natural 
institutional umbrella of choice for adherence to multinational homogeneous rules of accreditation of engineering education programs. Mutual recognition agreements with signatory countries, or membership within the Accord itself, should also be viewed as a desirable feature in an optimal institutional model for said agencies in Latin America and the Caribbean.

\section{CONCLUDING REMARKS}

In view of the arguments advanced above, we conclude that the characteristics of: (i) an outcome-oriented approach to accreditation; (ii) demand-driven criteria for judging quality; (iii) a profession-controlled organization; (iv) internationally homogeneous standards; and (v) an orientation toward the Washington Accord, are key features of an optimal institutional model for agencies accrediting the quality of engineering education.

\section{REFERENCES}

[1] Stake, R. E. Standards-Based and Responsive Evaluation, Thousand Oaks, CA, Sage Publications, 2004

[2] O.E.C.D DAC Working Party: Glossary of Key Terms in Evaluation and Results-based Management. pp. 33, 25, 28, and 24. 2010

[3] Latucca., Lisa R., et al. Engineering Change. A study of the impact of EC2000. Center for the Study of Higher Education, Pennsylvania State University, 2006

[4] OAS, Declaration of Lima. $1^{\text {st }}$ Meeting of Ministers and High Authorities of Science and Technology. REMCYT-I/DEC. 1/04. Nov 12,2004 